\title{
VARIABILIDADE GENÉTICA ENTRE ACESSOS DE AÇAIZEIRO UTILIZANDO MARCADORES MICROSSATÉLIŢES
}

\author{
Genetic variability among accessions of assai palm based on microsatellite markers
}

\author{
Maria do Socorro Padilha de Oliveira', João Bosco dos Santos ${ }^{2}$, \\ Edson Perito Amorim ${ }^{3}$, Daniel Furtado Ferreira ${ }^{4}$
}

\begin{abstract}
RESUMO
Conduziu-se este trabalho, com o objetivo de caracterizar a variabilidade genética entre 116 acessos de açaizeiro da coleção de germoplasma da Embrapa Amazônia Oriental por marcadores microssatélites (SSR). As reações foram efetuadas com base em 116 amostras de DNA, utilizando sete primers SSR. Os níveis de polimorfismo e as estimativas das distâncias genéticas de Roger foram determinados pelas frequências alélicas e agrupado pelo método UPGMA. Os sete locos SSR revelaram 42 alelos com média de 6 alelos por loco. O conteúdo de informação de polimorfismo (PIC) variou de 0,60 a 0,86 com média de 0,75 e as heterozigosidades observada $\left(\mathrm{H}_{\mathrm{o}}\right)$ e esperada $\left(\mathrm{H}_{\mathrm{e}}\right)$ foram de 0,54 e 0,75 , respectivamente. A distância genética média entre todos os acessos foi de 0,61 , variando de 0 a 0,96 . O método UPGMA formou seis agrupamentos distintos delimitados pela distância genética média $\left(\mathrm{dg}_{\mathrm{m}}=0,61\right)$. Os acessos de açaizeiro possuem alta diversidade para ser explorada em programas de melhoramento, sendo pelo menos quatro deles altamente divergentes com base nos marcadores SSR.
\end{abstract}

Termos para indexação: Euterpe oleracea, germoplasma, polimorfismo, diversidade genética, SSR.

\section{ABSTRACT}

The objective of this work was to characterize genetic variability among 116 accessions of assai palm of the Embrapa Eastern Amazon Germplasm Collection, were examined with microsatellite (SSR) markers. The 116 DNA sample were utilized in the reactions with seven SSR loci. The levels of polymorphism and Roger's genetic distance were estimated from allele frequencies and clustered with the UPGMA method. The seven SSR loci revealed 42 alleles, with average of 6 alleles per locus. The polymorphic information content (PIC) varied from 0.60 to 0.86 , with average of 0.75 and observed $\left(\mathrm{H}_{\mathrm{o}}\right)$ and expected $\left(\mathrm{H}_{\mathrm{e}}\right)$ heterozygosities were 0.54 and 0.75 , respectively. The mean genetic distance between all accessions was 0.61 , varying from 0.00 to 0.96 . The UPGMA dendrogram presented six distinct groupings, delimited by the mean genetic distance $\left(\mathrm{dg}_{\mathrm{m}}=0.61\right)$. The accessions of assai palm possess high diversity that may be explored in breeding program and germplasm organization, with at least, four highly divergent accessions.

Index terms: Euterpe oleracea, germplasm, polymorphism, genetic diversity, SSR.

(Recebido em 26 de março de 2008 e aprovado em 14 de julho de 2009)

\section{INTRODUÇÃO}

O mercado de frutos do açaizeiro (Euterpe oleracea Mart.) para a comercialização da bebida açaí, nas últimas décadas, vem se expandindo no Brasil e no exterior ampliando a área plantada com essa fruteira na Amazônia e em outros estados do Brasil (Oliveira et al., 2007a). No entanto, pouco se conhece sobre o germoplasma dessa palmeira conservado em coleções que possa orientar programas de melhoramento genético, especialmente sobre a variabilidade genética disponível (Oliveira et al., 2007b; Oliveira et al., 2007c). A caracterização é uma atividade prioritária na estratégia de abordagem e manejo de coleções e bancos de germoplasma, pois consiste em tomar dados para descrever, identificar e diferenciar os acessos (Valls, 2007). Em se tratando de germoplasma de plantas perenes, como é o caso do açaizeiro, a caracterização é escassa e envolve descritores botânicos, morfológicos e agronômicos e, mais recentemente, os moleculares.

A caracterização molecular é realizada com vários objetivos, dentre eles têm-se a quantificação da diversidade e a determinação da estruturação genética da população, por fornecer estudo direto do genótipo detectando diferenças no DNA de utilidade no manejo de coleções de germoplasma e nas diferentes etapas de programas de melhoramento de plantas (Kraic et al., 2002; Bicalho et al., 2008; Almeida et al., 2009). Para a caracterização da

\footnotetext{
${ }^{1}$ Empresa Brasileira de Pesquisa Agropecuária/Embrapa - Embrapa Amazônia Oriental - Travessa Doutor Enéas Pinheiro - s/nº - Cx. P. 48 - 66095-100 Belém, PA - spadilha@cpatu.embrapa.br

${ }^{2}$ Universidade Federal de Lavras/UFLA - Departamento de Biologia/DBI - Lavras, MG

${ }^{3}$ Empresa Brasileira de Pesquisa Agropecuária/Embrapa - Embrapa Mandioca e Fruticultura - Cruz das Almas, BA

${ }^{4}$ Universidade Federal de Lavras/UFLA - Departamento de Ciências Exatas/DEX - Lavras, MG
} 
diversidade, há vários marcadores moleculares disponíveis, sendo os que usam a técnica PCR (Polymerase Chain Reaction), como os microssatélites ou SSR (Single Sequence Repeat), os mais utilizados pelo seu elevado conteúdo informativo, sua robustez analítica e transferibilidade, sendo altamente indicados para uso em espécies florestais por serem altamente heterozigotas (Grattapaglia, 2007). Esses marcadores são relativamente novos, baseados em sequências curtas, contêm de 1 a 6 pares de bases repetidas lado a lado no genoma, são codominantes, múltialélicos, com análise de polimorfismos relativamente simples, necessitam de pequenas quantidades de DNA nas reações, além de serem plenamente transferíveis entre indivíduos dentro de uma espécie, entre espécies taxonômicas e até mesmo de gêneros distintos e compartilhados entre diferentes laboratórios (Gaiotto et al., 2001; Grattapaglia, 2007).

Marcadores microssatélites têm sido utilizados com sucesso na caracterização da diversidade (Milach, 1998). No Brasil, têm sido aplicados na diversidade genética de algumas coleções de germoplasma (Faleiro et al., 2001; Alves et al., 2003; Conte et al., 2006). Mas, não há registro de seu uso na caracterização de acessos existentes em bancos ou coleções de germoplasma da espécie em questão. Contudo, recentemente, foram desenvolvidos para Euterpe edulis Mart. 18 primers SSR e sete deles mostraram-se transferíveis para E. oleracea Mart. (Gaiotto et al., 2001).

Objetivou-se, neste trabalho, caracterizar a variabilidade genética entre acessos de açaizeiro da coleção de germoplasma da Embrapa Amazônia Oriental por meio de marcadores microssatélites.

\section{MATERIAL E MÉTODOS}

Foram retirados folíolos da folha mais jovem de 116 acessos de açaizeiros coletados em diferentes procedências e ambientes dos estados do Pará, Maranhão e Amapá (Tabela 1). Esses acessos encontram-se conservados na forma in vivo no banco de germoplasma da Embrapa Amazônia Oriental, Belém, PA (1²7’21"S, $48^{\circ} 30^{\prime} 16^{\prime \prime} \mathrm{W}$ e $10,8 \mathrm{~m}$ de altitude), desde novembro de 1985, em Latossolo Amarelo textura média, dispostos em linhas, no espaçamento de $5 \mathrm{~m} \mathrm{x} 3 \mathrm{~m}$. O clima local, segundo a classificação de Koppen, corresponde ao tipo quente e úmido ( $\mathrm{Af}_{\mathrm{i}}$ ), caracterizado por uma estação chuvosa com precipitação média de $2.740 \mathrm{~mm}$, temperatura média de $26^{\circ} \mathrm{C}$ e umidade relativa do ar próxima de $90 \%$. Após a coleta, os folíolos foram embalados em sílica gel e enviados ao Laboratório de Genética Molecular do Departamento de Biologia da Universidade Federal de Lavras (UFLA) para a extração do DNA.
A extração do DNA genômico foi realizada com base no protocolo de Nienhuis et al. (1995), utilizando-se cerca de $1 \mathrm{~g}$ de folha seca de cada amostra. Após esse processo, as 116 amostras de DNA foram quantificadas em fluorímetro, diluídas em TE para a concentração de $10 \mathrm{ng} \mu \mathrm{L}^{-1}$ e armazenadas a $-20^{\circ} \mathrm{C}$. As amostras foram genotipadas para sete locos SSR, que apresentaram transferibilidade de E. edulis para E. oleracea sendo desenvolvidos por Gaiotto et al. (2001) e sintetizados pela Invitrogen Life Tecnologies (Tabela 2). O volume das reações foi de $17 \mu \mathrm{L}$ e seguiu procedimento semelhante ao utilizado por Nienhuis et al. (1995), sendo constituído por: 33 ng do DNA genômico, $50 \mu \mathrm{M}$ de cada um dos desoxirribonucleotídeos trifosfatos (dATP, dCTP, dGTP, dTTP); 0,18 $\mu \mathrm{M}$ de cada par de primer (Forward e Reverse); 2,75 unidades da enzima Taq DNA polimerase mais tampão de reação $(50 \mathrm{mM}$ de tris com pH 8, 2 mM de $\mathrm{MgCl}_{2}, 20 \mathrm{mM}$ de $\mathrm{KCl}, 250 \mu \mathrm{g} \mathrm{mL}^{-1}$ de albumina de soro bovino, $1 \%$ de ficoll 400 e $1 \mathrm{mM}$ de tartrazine) e colocado em microtubo com capacidade de $0,2 \mathrm{~mL}$.

As amplificações foram efetuadas em termociclador Mastercycler Gradiente 5331 (Eppendorf), programado com desnaturação do DNA a $95^{\circ} \mathrm{C}$ por dois minutos, seguida de 32 ciclos. Cada ciclo foi constituído pela desnaturação a $94^{\circ} \mathrm{C}$ por 20 segundos; anelamento variando de $50^{\circ} \mathrm{C}$ a $64^{\circ} \mathrm{C}$, conforme o primer (Tabela 2) por 20 segundos; alongamento a $72^{\circ} \mathrm{C}$ por 20 segundos e extensão final a $72^{\circ} \mathrm{C}$ por dez minutos. Os produtos da amplificação foram separados em gel de agarose ultrapura 1000 (Invitrogen), a 2,5\% em eletroforese horizontal com tampão TBE $0,5 \mathrm{X}$, em voltagem constante de $100 \mathrm{~V}$, por 2 horas e 45 minutos. Os géis foram tratados com brometo de etídeo numa concentração de $0,5 \mu \mathrm{g} \mathrm{mL}^{-1}$, visualizados em transiluminador de luz ultravioleta Fotodyne. As imagens foram capturadas em câmera digital e armazenadas em computador para avaliação dos padrões de bandas.

As bandas foram codificadas primeiramente por 1 (presença) e 0 (ausência), e, depois, lidas como dados genotípicos para a identificação de todos os alelos por loco. O nível de polimorfismo e as estimativas dos coeficientes de dissimilaridades genéticas entre o $i$-ésimo e o $j$-ésimo acesso foram obtidos no software TFPGA v. 1,3, a partir das frequências alélicas. A distância utilizada foi a de Roger $\left(\hat{d} R_{i j}\right)$, conforme Reif et al. (2005). O conteúdo de informação de polimorfismo (PIC) foi obtido com base na equação: $\mathrm{PIC}=1-\sum_{i=1}^{t} p_{i}^{2}-2 \sum_{i=j+1}^{t} \sum_{j=1}^{t-1} p_{i}^{2} p_{j}^{2}$, onde $p_{i} \mathrm{e}$ $p_{j}$ são as frequências do $i$-ésimo e do $j$-ésimo alelos em 
um loco com $t$ alelos em um acesso, respectivamente (Weir, 1996).

O agrupamento dos 116 acessos foi gerado pelo método hierárquico da média não ponderada-UPGMA (Unweighted pair-group method with arithmetic averages), a partir da matriz de distâncias genéticas no procedimento
SAHN do software NTSYS-pc 2,1. Os grupos geneticamente distintos foram identificados no dendrograma pelo ponto de corte feito em relação à distância genética média $\left(d g_{m}\right)$, obtida pela equação $d g_{m}=\sum d g_{i j} / N$, em que $\sum d g_{i j}=$ somatório das distâncias genéticas entre cada par de acessos e $N=$ número total de pares.

Tabela 1 - Identificação dos 116 acessos de açaizeiro conservados no Banco de Germoplasma da Embrapa Amazônia Oriental, Belém (PA) utilizados neste estudo.

\begin{tabular}{|c|c|c|}
\hline $\mathrm{N}^{\mathrm{o}}$ dos acessos & Procedência & Ambiente \\
\hline 1 e 2 & Benfica, PA & Pomar caseiro \\
\hline 3 e 4 & Benevides, PA & Pomar caseiro \\
\hline 5 e 7 & Benevides, PA & Propriedade rural \\
\hline 6 & Mosqueiro, PA & Pomar caseiro \\
\hline $8,9,10,11$ e 12 & $\mathrm{St}^{\circ} \mathrm{Ant}^{\mathrm{o}}$ do Tauá, PA & Propriedade rural \\
\hline $13,14,15,16,17,18,19,20,21,22,23,24,25,26$ e 27 & Chaves, PA & População natural \\
\hline $28,29,30,31,32,33,34,35,36,37$ e 38 & Muaná, PA & Propriedade rural \\
\hline $\begin{array}{l}39,40,41,42,43,44,45,46,47,48,49,50,51,52,53,54,55,56, \\
57,58,59,60,61,62,63,64,65,66,67 \text { e } 68\end{array}$ & Breves, PA & População natural \\
\hline 88 e 89 & Breves, PA & Propriedade rural \\
\hline $83,84,85,86$ e 87 & Gurupá, PA & Pomar caseiro \\
\hline 90 & Melgaço, PA & Propriedade rural \\
\hline 91 & Santarém, PA & Propriedade rural \\
\hline 93 & Santarém, PA & Pomar caseiro \\
\hline 92 & Prainha, PA & Pomar caseiro \\
\hline 109 & $\mathrm{St}^{\mathrm{a}} \mathrm{M}^{\mathrm{a}}$ do Pará, PA & População natural \\
\hline $110,111,112,113$ e 114 & Cametá, PA & População natural \\
\hline $69,70,72$ e 73 & Oiapoque, AP & População natural \\
\hline $76,78,79,80$ e 82 & Oiapoque, AP & Pomar caseiro \\
\hline $71,74,75,77$ e 81 & Macapá, AP & Pomar caseiro \\
\hline 94 & Carutapera, MA & Propriedade rural \\
\hline 95 e 96 & Maracaçumé, MA & Propriedade rural \\
\hline 97 & $\mathrm{St}^{\mathrm{a}}$ Luzia, MA & Propriedade rural \\
\hline 98 & Zé Doca, MA & Propriedade rural \\
\hline 99 e 100 & Turiaçu, MA & População natural \\
\hline 101 & $\mathrm{St}^{\mathrm{a}}$ Inêz, MA & População natural \\
\hline 102 & Cururupu, MA & Pomar caseiro \\
\hline 103 e 104 & Mirinzal, MA & População natural \\
\hline 105 e 106 & Guimarães, MA & População natural \\
\hline 107 & Alcântara, MA & População natural \\
\hline 108 & Alcântara, MA & Pomar caseiro \\
\hline 115 e 116 & Linhares, ES & Intercâmbio \\
\hline
\end{tabular}


Tabela 2 - Identificação dos sete pares de primers microssatélites desenvolvidos para Euterpe edulis Mart. por Gaiotto et al. (2001) e transferíveis para o açaizeiro (Euterpe oleracea Mart.).

\begin{tabular}{|c|c|c|c|c|}
\hline Primers & Repetições & Sequência dos primers $\left(5^{\prime} \rightarrow 3^{\prime}\right)$ & \multicolumn{2}{|c|}{ Temperatura de anelamento $\left({ }^{\circ} \mathrm{C}\right)$} \\
\hline EE2 & $(\mathrm{AG})_{22}$ & $\begin{array}{l}\text { F: CCAAGGACGCAATCTCAA } \\
\text { R: AGCGAGGCAGAACACGTA }\end{array}$ & $62^{(1)}$ & $56^{(2)}$ \\
\hline EE3 & $\begin{array}{l}(\mathrm{AG})_{11} \\
(\mathrm{AG})_{16}\end{array}$ & $\begin{array}{l}\text { F: TTCGCGCACACTGAGAG } \\
\text { R: GGTAGCGTTGATTGGTCC }\end{array}$ & 56 & 56 \\
\hline EE8 & $(\mathrm{AG})_{20}$ & $\begin{array}{l}\text { F: GTATTCCAATGTGCTCACAG } \\
\text { R: GTGCAGTAGGCTTCTAGTACC }\end{array}$ & 58 & 52 \\
\hline EE15 & $(\mathrm{AG})_{21}$ & $\begin{array}{l}\text { F: CCACACAGACACGCAGATAG } \\
\text { R: CCTCATGAAGCATCGACCT }\end{array}$ & 64 & 64 \\
\hline EE23 & $(\mathrm{A})_{14}(\mathrm{AG})_{23}$ & $\begin{array}{l}\text { F: GTTCTGCGATTCATACTCCTG } \\
\text { R: TACGAACCAAGATGGAGCAA }\end{array}$ & 58 & 56 \\
\hline EE43 & $(A G)_{16}$ & $\begin{array}{l}\text { F: GCGAAAGGCTAACAACGTTAT } \\
\text { R: AGCGAACCAACCAAGAAGAC }\end{array}$ & 56 & 50 \\
\hline EE54 & $(\mathrm{AG})_{25}$ & $\begin{array}{c}\text { F: CATGTATCTAAGGAACAAGG } \\
\text { R: CTGTGCTCTCTCATTCTCA }\end{array}$ & 56 & 50 \\
\hline
\end{tabular}

\section{RESULTADOS E DISCUSSÃO}

Os sete marcadores microssatélites utilizados na genotipagem nas 116 amostras de açaizeiro foram todos polimórficos, de fácil identificação nos géis e amplificaram 42 alelos, com variação de três a dez alelos por loco e média de seis alelos (Tabela 3). Na maioria dos locos, o conteúdo de informação de polimorfismo (PIC) foi elevado, variando de 0,60 a 0,86 com média de 0,75 . A magnitude da correlação entre o PIC e o número de alelos também foi alta e significativa $(\mathrm{r}=0,78, \mathrm{P} \leq 0,04)$, existindo uma relação direta entre eles, ou seja, quanto maior no número de alelos, maior será o valor do PIC. Elevados níveis de polimorfismos também foram detectados por Gaiotto et al. (2003) e Conte et al. (2006) ao utilizarem os mesmos primers em populações de palmiteiro (Euterpe edulis). Germoplasma de outras palmeiras também apresentam alta diversidade quando analisados com marcadores microssatélites (Perera et al., 2000, 2001; Meerow et al., 2003; Zehdi et al., 2004a,b). Como o PIC fornece uma estimativa do poder discriminatório de um marcador (Weir, 1996), pode-se inferir que os marcadores utilizados foram eficientes na discriminação dos acessos.

Para as heterozigosidades esperadas $\left(\mathrm{H}_{\mathrm{e}}=0,60 \mathrm{a}\right.$ 0,85 ) foram constatados altos valores em todos os locos com média de 0,75 . No caso das observadas os valores variaram de médios a altos $\left(\mathrm{H}_{\mathrm{o}}=0,51\right.$ a 0,99$)$ com exceção dos locos EE3 e EE 43, que exibiram os menores valores, em consequência do menor número de alelos. Heterozigosidades observadas com valores altos foram constados por Gaiotto et al. (2003), entre indivíduos de duas populações naturais de Euterpe edulis. De acordo com Weir (1996), espera-se que o valor do PIC seja similar ao da estimativa da heterozigosidade esperada $\left(\mathrm{H}_{\mathrm{e}}\right)$, sendo ambos sinôminos de diversidade genética, podendo-se considerar que os acessos utilizados neste trabalho sejam detentores de alta variabilidade nos locos testados.

Os resultados obtidos confirmam o sucesso da transferibilidade de locos SSR de Euterpe edulis para $E$. oleracea constatado por Gaiotto et al. (2001), uma vez que os sete locos testados apresentaram $100 \%$ de aproveitamento. Grattapaglia (2007) considera a transferibilidade entre espécies do mesmo gênero como uma característica desejável dos marcadores SSR. No trabalho em questão, houve a necessidade de ajustes (redução) na temperatura de anelamento de alguns primers (Tabela 2), assim como no volume e na quantidade dos componentes da reação de PCR. Alves et al. (2003) também precisaram otimizar os procedimentos ao transferirem locos de Theobroma cacao L. para T. grandiflorum (Willd. ex Spreng.) K. Schum. e consideraram-nas como baixa a divergência evolutiva. A mesma inferência pode ser utilizada para as espécies E. edulis e E. oleracea.

$\mathrm{Na}$ matriz de distâncias genéticas formada pelos 116 acessos foram obtidos valores altamente variáveis, indo desde totalmente similares (0) a quase dissimilares $(0,96)$ e com distância genética média entre todos os acessos de 0,61. Os 6.670 pares gerados pela matriz são 
apresentados na forma de distribuição de frequência na Figura 1, onde se observa que as doze classes exibiram forte assimetria à direita, pois poucos pares $(0,5 \%)$ ficaram incluídos nas três primeiras classes e o maior número de pares $(82,8 \%)$ ficou contido entre a $7^{\mathrm{a}}$ e a $10^{\mathrm{a}}$ classe. A forte variação observada pode estar relacionada aos ambientes de coleta dos acessos que estão localizados no centro de diversidade da espécie (Oliveira et al., 2007a). Analisando a divergência genética entre 87 acessos desse mesm banco com base em descritores morfoagronômicos, Oliveira et al. (2007b) também encontraram distribuição semelhante e consideraram nove acessos como altamente divergentes. Esses autores ainda verificaram que os acessos analisados apresentavam características desejáveis para a produção de frutos. Tais resultados permitem sugerir que indivíduos, pelo menos, desses nove acessos possam ser indicados para programas de melhoramento genético para frutos.

O dendrograma formou grupos com vários subgrupos (Figura 2) e apresentou valor cofenético alto $(\mathrm{r}=0,67, \mathrm{P}<0,0001)$, o que indica boa concordância com os valores de distância genética. Com base no ponto de corte $\left(d g_{m}=0,61\right)$ foi possível distinguir seis grupos geneticamente distintos com o $1^{\circ}$ e o $4^{\circ}$ constituídos por três $(100,99$ e 40) e quatro $(115,113,98$ e 97$)$ acessos, respectivamente; e o $6^{\circ}$ por quase a metade dos acessos amostrados. Para a espécie em questão, também foi detectada a formação de poucos grupos com o uso de descritores morfoagronômicos (Gazel Filho \& Lima, 2006;

Tabela 3 - Nível de polimorfismo dos 116 acessos de açaizeiro do Banco de Germoplasma da Embrapa Amazônia Oriental com base nos sete locos microssatélites.

\begin{tabular}{ccccc}
\hline Primers & $\mathrm{N}^{\mathrm{o}}$ de alelos & $\mathrm{PIC}^{(1)}$ & $\mathrm{H}_{\mathrm{e}}$ & $\mathrm{H}_{\mathrm{o}}$ \\
\hline EE2 & 4 & 0,64 & 0,64 & 0,56 \\
EE3 & 3 & 0,60 & 0,60 & 0,04 \\
EE8 & 6 & 0,81 & 0,81 & 0,72 \\
EE15 & 6 & 0,80 & 0,79 & 0,63 \\
EE23 & 10 & 0,86 & 0,85 & 0,51 \\
EE43 & 5 & 0,73 & 0,72 & 0,33 \\
EE54 & 8 & 0,86 & 0,86 & 0,99 \\
\hline Média & 6 & 0,75 & 0,75 & 0,54 \\
\hline
\end{tabular}

(1): conteúdo de informação de polimorfismo; $\mathrm{H}_{\mathrm{e}}$ e $\mathrm{H}_{\mathrm{o}}$ : Heterozigosidades esperada e observada, respectivamente.

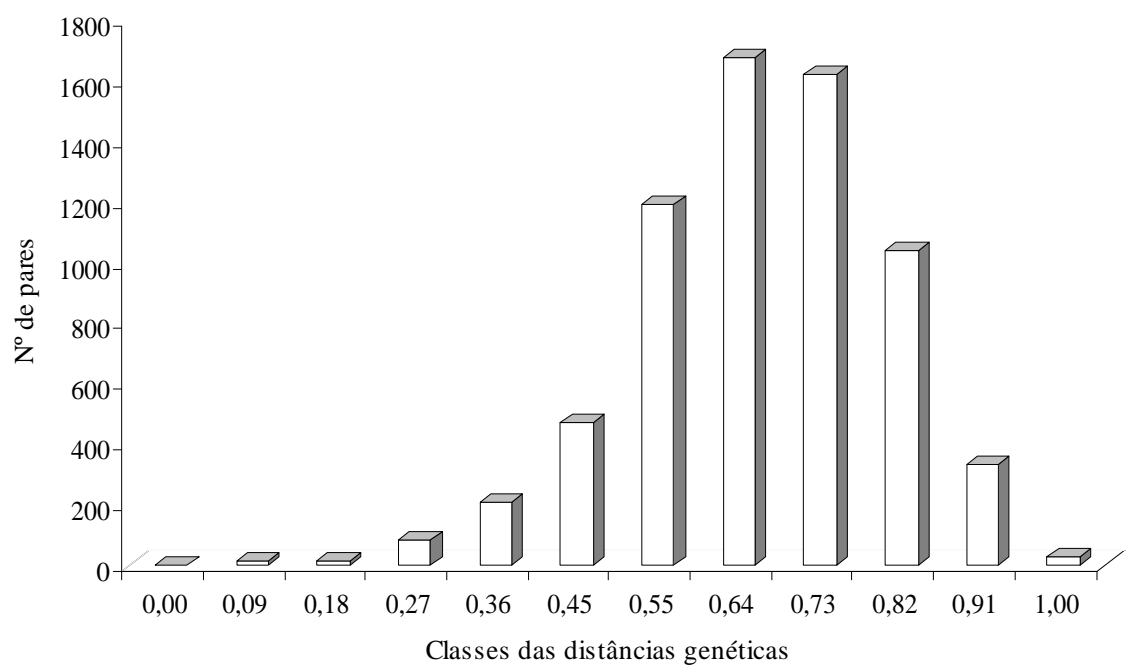

Figura 1 - Frequência das distâncias genéticas obtidas entre os 6.670 pares gerados pelos 116 acessos de açaizeiro do Banco de Germoplasma da Embrapa Amazônia Oriental. 


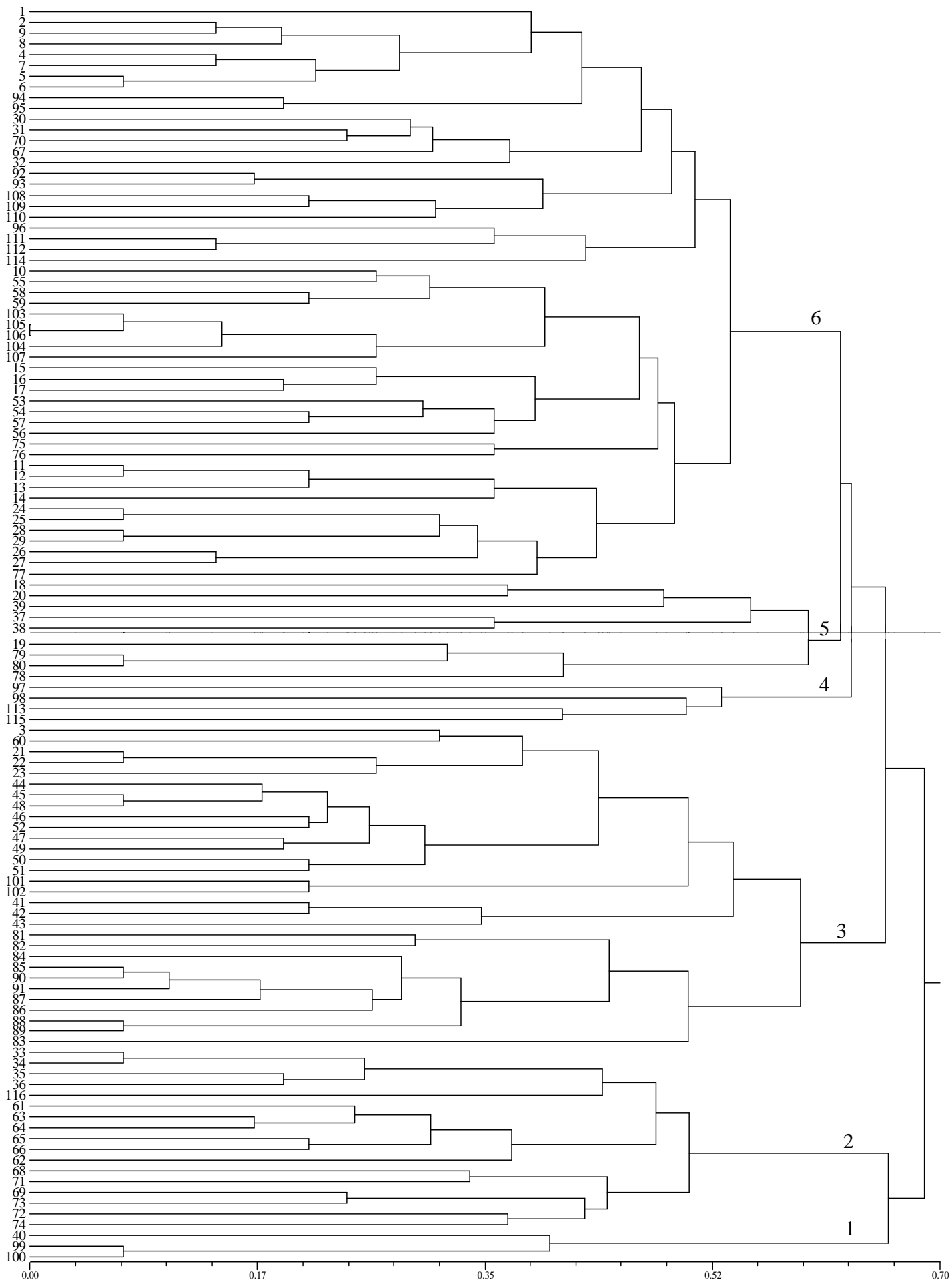

Figura 2 - Dendrograma das distâncias genéticas entre os 116 acessos de açaizeiro do Banco de Germoplasma da Embrapa Amazônia Oriental com os 42 alelos obtidos dos sete locos SSR, $d g_{m}=0,61$. 
Oliveira et al., 2007b) e por marcadores RAPD (Oliveira et al., 2007c). Tais resultados permitem inferir que acessos do $1^{\circ}$ e $6^{\circ}$ grupos podem ser interessantes para cruzamentos, por serem geneticamente distantes, especialmente entre os acessos do 40, 99 e 100 e o acesso 1, esse último considerado por Oliveira et al. (2007b) como o menos divergente dos 87 acessos que formaram cinco grupos. Oliveira et al. (2007c) também detectaram alta divergência entre os acessos 99 e 100 por marcadores RAPD.

Os acessos 115 e 116 possuidores de genoma híbrido (Euterpe oleracea e E. espiritossantensis Fernandes) foram alocados em grupos distintos, $4^{\circ}$ e $2^{\circ}$, respectivamente (Figura 2). Em uma análise geral, observase que alguns acessos foram agrupados por procedência ou local de coleta, mas essa tendência não foi observada para a grande maioria. Resultados semelhantes foram obtidos no agrupamento de acessos de coqueiro (Perera et al., 2001; Meerow et al., 2003; Zehdi et al., 2004b) e de cacaueiro (Faleiro et al., 2001) por meio de marcadores microssatélites.

Ainda no dendrograma, também foi detectada a formação de doze pares de acessos com alta proximidade genética ( $>10 \%)$, mas que se organizaram em grupos distintos: um par nos grupos 1 (acessos 99 e 100), 2 (acessos 33 e 34) e 5 (acessos 79 e 80); quatro pares no grupo 3 (acessos 88 e 89; 85 e 90; 45 e 48; 21 e 22) e os demais no grupo 6 (acessos 28 e 29; 24 e 25; 11 e 12; 103, 105 e 106; 5 e 6). Nesse último grupo, foi registrado um par de acessos idênticos (105 e 106). Essa similaridade pode estar associada ao fato dos acessos terem a mesma procedência e ambiente de coleta, enquanto a constatada entre pares geograficamente distantes pode ser explicada pela ação antrópica e pela ação dos rios na disseminação de sementes.

\section{CONCLUSÕES}

Os acessos de açaizeiro caracterizados por marcadores microssatélites apresentam ampla diversidade genética e podem ser úteis na formação de coleção núcleo dessa espécie.

Os acessos do $1^{\circ}$ e $6^{\circ}$ grupos considerados geneticamente mais distantes desse Banco de Germoplasma podem ser indicados para compor programas de melhoramento genético, especialmente, aqueles que também possuem características desejáveis para frutos.

\section{REFERÊNCIAS BIBLIOGRÁFICAS}

ALMEIDA, C.M.A de.; LIMA, S.E.N de.; LIMA, G.S de A.; BRITO, J.Z de.; DONATO, V.M.T.S.; SILVA, M.V da. Caracterização molecular de cultivares de cana-de-açúcar utilizando marcadores ISSR. Ciência e Agrotecnologia, Lavras, v. 33, Edição Especial, p. 1771 -1776, 2009.

ALVES, R.M.; ARTERO, A.S.; SEBBENN, A.M.; FIGUEIRA, A. Mating system in a natural population of Theobroma grandiflorum (Willd. ex Spreng.) Schum., by microsatellite markers. Genetics and Molecular Biology, Ribeirão Preto, v.26, p.373-379, 2003.

BICALHO, K.C.; OLIVEIRA, L.E.M de; SANTOS, J.B dos; MESQUITA, A.C.; MENDONÇA, E.G. Similaridade genética entre clones de seringueira (Hevea brasiliensis), por meio de marcadores RAPD. Ciência e Agrotecnologia, Lavras, v.32, n.5, p.1510-1515, set./out., 2008.

CONTE, R.; REIS, M.S.; VENCOVSKY, R. Effects of management on the genetic structure of Euterpe edulis Mart. populations based on microsatellites. Scientia Forestalis, Piracicaba, v.72, p.81-88, 2006.

FALEIRO, F.G.; LOPES, U.V.; YAMADA, M.M.; PIRES, J.L.; BAHIA, R.C.S.; SANTOS, R.C.; GOMES, L.M.C.; ARAÚJO, I.S.; FALEIRO, A.S.G.; GRAMACHO, K.P.; MELO, G.R.P.; MONTEIRO, W.R.; VALE, R.R. Caracterização de variedades clonais de Theobroma cacao L com base em marcadores RAPD, AFLP e microssatélites. Agrotrópica, Salvador, v.13, p.79-86, 2001.

GAIOTTO, F.A.; BRONDANI, R.P.V.; GRATTAPAGLIA, D. Microsatellite markers for heart of palm Euterpe edulis and E. oleracea Mart. (Palmae). Molecular Ecology Notes, Oxford, v.1, p.86-88, 2001.

GAIOTTO, F.A.; GRATTAPAGLIA, D.; VENCOVKSY, R. Genetic struture, mating system, and long-distance gene flow in heart of palm (Euterpe edulis Mart.). Journal of Heredity, Carey, v.94, p.399-406, 2003.

GAZEL FILHO, A.B.; LIMA, J.A. de S. Diversidade genética de matrizes de açaizeiro (Euterpe oleracea Mart.). In: FRAZÃO, D.A.C.; HOMMA, A.K.O.; VIÉGAS, I. de J.M. (Eds.). Contribuição ao desenvolvimento da fruticultura da Amazônia. Belém: Embrapa Amazônia Oriental, 2006. p.69-72.

GRATTAPAGLIA, D. Aplicações operacionais de marcadores moleculares. In: BORÉM, A. (Ed.). Biotecnologia florestal. Viçosa, MG: UFV, 2007. p.175-200. 
KRAIC, J.; GREGOVÁ, E.; JOMOVÁ, K.; IIUDCOVICOVÁ, M. Microsatellite markers discriminating accessions within collections of plant genetic resources. Cellular \& Molecular Biology

Letters, Wroclaw, v.7, p.745-751, 2002.

MEEROW, A.W.; WISSER, R.J.; BROWN, J.S.; KUHN, D.N.; SCHNELL, R.J.; BROSCHAT, T.K. Analysis of genetic diversity and population structure within Florida coconut (Cocos nucifera L.) germplasm using microsatellite DNA, with special emphasis on the Fiji Dwarf cultivar. Theoretical and Applied Genetics, Berlin, v.106, p.715-726, 2003.

NIENHUIS, J.; TIVANG, J.; SCKROCH, P.; SANTOS, J.B. dos. Genetic relations among cultivars and lines of lima bean (Phaseolus lunatus L.) as measured by RAPD marker. Journal of American Society for Horticultural Science, Alexandria, v.120, p.300-306, 1995.

OLIVEIRA, M. do S.P. de; FARIAS NETO, J.T.; PENA, R. da S. Açaí: técnicas de cultivo e processamento. Fortaleza: Instituto Frutal, 2007a. $104 p$.

OLIVEIRA, M. do S.P de; FERREIRA, D.F.; SANTOS, J.B. dos. Divergência genética entre acessos de açaizeiro fundamentada em descritores morfoagronômicos. Pesquisa Agropecuária Brasileira, Brasília, v.42, n.4, p.501-506, 2007b.

OLIVEIRA, M. do S.P de; AMORIM, E.P; SANTOS, J.B. dos; FERREIRA, D.F. Diversidade genética entre acessos de açaizeiro baseada em marcadores RAPD. Ciência e agrotecnologia, Lavras, v. 31, n. 6, p. 16451653, nov./dez., 2007c.
PERERA, L.; RUSSELL, J.R.; PROVAN, J.; POWELL, W. Levels and distribution of genetic diversity of coconut (Cocos nucifera L., var. Typica form typica) from Sri Lanka assessed by microsatellite markers. Euphytica, Wageningen, v.122, p.381-389, 2001.

PERERA, L.; RUSSELL, J.R.; PROVAN, J.; POWELL, W. Use of microsatellite DNA markers to investigate the level of genetic diversity and population genetic structure of coconut (Cocos nucifera L.). Genome, Ontario, v.43, p.15-21, 2000.

REIF, J.C.; MELCHONGER, A.E.; FRISCH, M. Genetical and mathematical properties of similarity and dissimilarity coefficients applied in plant breeding and seed bank management. Crop Science, Madison, v.45, p.1-7, 2005.

VALLS, J.F.M. Caracterização de recursos genéticos vegetais. In: NASS, L.L. (Editor técnico). Recursos genéticos vegetais. Brasília: Embrapa Recursos Genéticos e Biotecnologia, 2007. cap. 8, p.281-305.

WEIR, B.S. Genetic data analysis: methods for discretion population genetic data. Sunderland: Sinauer Associates, 1996. 377p.

ZEHDI, S.; SAKKA, H.; RHOUMA, A.; OULD MOHAMED SALEM, A.; MARRAKCHI, M.; TRIFI, M. Analysis of Tunisian date palm germplasm using simple sequence repeat primers. African Journal of Biotechnology, Pretoria, v.3, p.215-219, 2004a.

ZEHDI, S.; TRIFI, M.; BILLOTTE, N.; MARRAKCHI, M.; PINTAUD, J.C. Genetic diversity of Tunisian date palm (Phoenix dactylifera L.) revealed by nuclear microsatellite polymorphism. Hereditas, Amsterdam, v.141, p.278-287, 2004b. 